\title{
Quality assurance practices in university libraries in South Africa
}

\author{
Luyanda Dube' \\ Department of Information Science, University of South Africa, Pretoria, South Africa \\ dubel@unisa.ac.za
}

\begin{abstract}
Received: 17 December 2010
Accepted: 10 April 201I

Key to the transformation of the South African higher education landscape has been the introduction and enhancement of quality assurance practices. The implementation of quality assurance mechanisms in the sector has also affected academic libraries, as they are not static, free-standing entities but are part of universities and their academic culture. Evidently, quality assurance is no longer an option, but a critical reality as libraries in general are under immense pressure to prove their worth in competition with other information enterprises, and are also facing budget cuts (Kinnell, Usherwood, \& Jones 1999; Tam 2000). Academic libraries, in particular, are facing the extra challenge of striving to align quality initiatives and practices not only with the overall mission and goals of the university, but also with the "fitness for purpose" quality principle by which universities are judged by the Higher Education Quality Committee (HEQC). The study utilised questionnaires and document analysis to collect data and targeted officers in academic libraries who deal with quality assurance matters or issues as well as policy or other related documents. The results showed that quality assurance practices in academic libraries vary. They range from active and integrative processes for maintaining and improving quality to those that are feeble and not well developed. However, there is general commitment towards instilling a quality culture, encouraging a best practice, participative approach, continuous improvement and satisfying the needs of the customer. As one of its recommendations, the study highlights the need to enhance the depth and breadth of quality assurance initiatives and to create more avenues for sharing best practices.
\end{abstract}

Keywords: Quality; quality assurance; academic libraries and higher education landscape

\section{Introduction}

According to the national higher education transformation agenda, universities in South Africa have been charged with the responsibility of transforming into institutions that produce graduates that will contribute meaningfully to the new social, economic and political order (Department of Education 1997). Key to the process of transforming the South African higher education landscape has been the introduction and enhancement of quality assurance practices. Quality assurance is a planned and systematic process for evaluating structures, systems, services, processes and people to ensure that best practices are encouraged through continuous improvement, accountability, participative approach and delivery of quality products which are relevant and responsive to the needs of the customer (McGregor 2004). Furthermore, it is an active, integrative and developmental process that entails instilling, maintaining and improving a quality culture by examining the structures, systems, services, processes and people in an organisation with the intent of satisfying internal and external customers.

It has emerged from reviewed literature that the term "quality" is a relative term which can be interpreted differently under different contexts. Because of the multiple definitions that have been forwarded, the term "quality" is shrouded in ambiguity which necessitates the provision of a definition or definitions in line with the context of this paper. The paper adopts the definition of quality as espoused by the South African and Australian higher education landscapes wherein the definition of quality is based largely on the premise of "fitness for purpose". Winkworth (200I) highlights that the fitness for purpose principle encompasses the following: effectiveness in achieving institutional goals and objectives as well as value for money, whereby the customers' stated or implied needs are met. Further, UNESCO (2006) states that an organization is fit for its purpose if:

i) There are procedures in place that are appropriate for the specified purpose(s).

ii) There is evidence that these procedures are in fact achieving the specified purpose(s).

It must be stated that the fitness for purpose approach or model to defining, understanding and measuring quality has been criticised in some circles, because the level at which the purpose(s) is pitched can strengthen or compromise the institution's mandate and commitment to quality assurance. Therefore, for this approach to be meaningful, the institution needs to pitch the purpose at an appropriate level.

As indicated in the literature, there are generally multiple benefits of measuring quality such as instilling a quality culture, encouraging best practice, accountability, participative approach, continuous improvement and satisfying the needs

I. Luyanda Dube $(\mathrm{PhD})$ is a senior lecturer in the Department of Information Science, University of South Africa, Pretoria, South Africa. 
of the customer. Providing quality services is critical; McGregor (2004) asserts that it will ensure that academic libraries remain relevant and central to the academic mission by demonstrating that they are not only essential to the success of teaching and learning and research, but are of strategic importance in achieving the university's mission and goals.

\section{Statement of the problem}

The basis of the problem that informs the study is two-fold. Firstly, after 1994 the introduction of quality initiatives in the higher education sector brought about the realisation that quality assurance is a reality for a university and its entities. Before the roll out of the HEQC quality assurance system, South African academic libraries did not have a clearly defined quality assurance model or framework for evaluating quality; each library was doing its own thing. Generally, the HEQC institutional audits were evidence-based this obviated the need for academic libraries to develop a synchronized effort to respond to the quality agenda (Gozo 2007). Subsequently, the Committee for Higher Education Librarians of South Africa (CHELSA) was launched in June 2004 as a sub-Committee of the HEQC and as Gozo (2007) notes since its inception it has given impetus to the development of quality assurance in academic libraries in South Africa. It stands to be seen whether the framework and support provided by CHELSA has made inroads in enhancing and standardizing quality assurance practices in the sector beyond the institutional audits. Secondly, because of competing priorities from social, economic and technological fronts libraries are not only facing budget cuts and freezes, but also the loss of information monopoly which puts them in competition with other information enterprises (Kinnell, Usherwood \& Jones 1999; Snoj 200I; Balog 2009; Tiemensma 2009). This general puts them under immense pressure to prove that they are credible agencies that expend scarce resources appropriately showing value for money. Quality assurance with its emphasis on improving work processes and efficiency of services holds promise for libraries to improve their worth and justify their existence. In view of the above synopsis, the paper seeks to assess the extent and nature of quality assurance practices implemented by academic libraries in South Africa to date.

\section{Aims and objectives}

In the current climate of economic pressures and the need to demonstrate the value of outcomes, libraries cannot rely on a general perception that they are a "good thing" (Poll 2006). The paper aims to review the range of quality assurance practices academic libraries employed in relation to the fitness for purpose approach. To actualise this aim, the following objectives were developed:

- to examine quality assurance strategies used

- to determine challenges and innovativeness related to quality assurance

- to map out quality indicators used to measure quality in libraries

\section{Quality assurance in libraries: insights from the literature}

In most libraries measuring quality is still limited to quantitative measures of outputs in terms of statistics related to users, hits, issues, requests and queries (Balog 2009; Tiemensma 2009). The assumption here is that increased outputs are an indication of improved quality. Qualitative measures on the other hand include have the ability to dig deeper asking pertinent questions related to outputs and outcomes such as, what the library does, how it does it, why it does it and how better results can be achieved, more efficiently and more effectively (Vergueiro \& Carvalho n.d.). Measuring of outcomes in particular represents a new dimension that seeks to endorse that the use of library services and products should bring a change in skills, competencies, attitudes and behavior of the users in line with institutional aims and goals (Poll 2008). Notwithstanding the advantages of quantitative data obtained through statistics, qualitative measurements would be indicative of a shift from the counting of resources to conducting user surveys that would yield meaningful qualitative and quantitative results.

The epicenter of both qualitative and quantitative measures is the user as these are about improving satisfaction. Therefore it is critical that the user is given an opportunity to give answers or pointers on issues that pertain to his/her needs. Of importance is that user feedback or viewpoints should be integrated into planning, operations, systems and processes of the library. This will ensure not only the alignment between services with expectations, but also the strengthening of a culture of quality service and continuous improvement. Obviously for this to materialize there has to be a paradigm shift in terms of the organisational culture, leadership style and practice. The shift will enable libraries to be user oriented, competent, helpful, accurate, reliable, quick, current and accountable (Poll 2008). It is imperative that academic libraries should strive to achieve these positive outcomes in order to position themselves as reputable and worthy reservoirs of information.

4.1 Why quality assurance in academic libraries

The primary purpose of an academic library according to Mdlalose (2004) is to serve the curricular, research and community outreach functions of its parent organization. This it does by providing mastery of a variety of information 
forms and formats, creating appropriate conditions for independent learning for a diverse client base efficiently and effectively. Poll (2006) cautions the value of libraries is no longer self-evident because of information glut characterized by free web information, and users who are increasingly becoming independent in their information seeking. Because of their persistent non-distinct value and the high costs of funding them academic libraries need to demonstrate that they are not only essential to the success of teaching, learning and research but are also of strategic importance in achieving the university's mission and goals (Poll 2008). One way of proving their fitness for purpose is to strengthen the breadth and depth of quality assurance strategies. This entailed undertaking what McGregor (2004) refers to as a quality journey, which entails continuous evaluation of internal quality management systems in relation to inputs, outputs and outcomes off services. According to Gozo (2007) and ALA Standards for University Libraries (1989) inputs include raw materials like money, space, collection, equipment and staff, whereas outputs serve to quantify the work done outcomes focus on the consequence or visible result of using library services.

\subsection{Practicalities of assuring quality in academic libraries}

Since quality is an intangible phenomenon Majid, Anwar and Eisenschitz (2001), explain that it cannot be measured directly, but through an indicator that is a proxy, criteria or guide for direct measurement of quality which can be used to make judgments about quality. Therefore, quality indicators are variables that can be used to determine how well a library meets user requirements and expectations as well as operational and performance targets. Balog (2009) and Tiemensma (2009) maintain that there are various tools that libraries can use to measure quality in a meaningful manner. These are LibQUAL+ which is an internationally acclaimed tool used for measuring quality and for purposes of benchmarking, and in-house surveys. There is evidence that these tool have also been used by some universities in South Africa. To actualise its mandate of developing a synchronised response for institutional audits in 2005 CHELSA through one of its Subcommittees recommended that about seven academic libraries take part in a pilot web based satisfaction survey using LibQUAL+ (Moon 2007; Gozo 2007). Although this initial pilot had according to Moon (2007) peripheral problems with the tool regarding the relevance and applicability of certain questions to certain user groups, the results provided a reliable indication of the quality of a range of LIS activities in each institution. Subsequently in 2005 Measures for Quality (M4Q) was developed and in 2006 a guide for the self review of university libraries was developed (CHELSA 2006). The two documents provided a common framework of guidelines with indicators that can be used to evaluate quality in an academic library. Emphasis was made that the essence of these was to guide library quality evaluations without intending to be prescriptive (CHELSA 2006). Although these were means of crafting an orchestrated response for university libraries in preparation for HEQC audits, they are groundbreaking initiatives that can be populated and optimized as building blocks to quality management in the country for years to come.

\subsection{Quality indicators for libraries}

Below is a synopsis of indicators and attributes for each indicator. The quality indicators presented below have been adapted from Majid, Anwar and Eisenschitz (200I); Snoj and Petermanec (200I); Winkworth (200I); Vergueiro and de Calvarlho (n.d).; Zeithaml, Bitner and Gremler (2006) and Gozo (2007) and have adopted to suit the context of this paper.

\subsubsection{Skills mix and staff}

Academic libraries have a diverse user base ranging from first year students to advanced researchers as a result they need specialist knowledge to select, acquire, process and organize the library's collection and provide access to physical and remote collections. Vergueiro and de Calvarlho (n.d.) highlight the fact that staff skills, knowledge and attitudes as well as their satisfaction levels have a direct impact on the quality of service, therefore, appropriate staffing is essential if the library is to perform efficiently. Although McGregor (2004) asserts that sometimes there is a predisposition that library staff have an inbuilt service ethic, this cannot be assumed to be present it must instilled in staff in various ways including measurement, evaluation, training and development. The following are attributes that staff should have:

- Courtesy: Polite, respectful and friendly employees to customers these are similar to government customer services known as Batho Pele Principles.

- Knowledgeability: Evidence of staff knowledge of the product and ability to convey trust and confidence.

- Promptness: Speed of services and response time.

- Communication: Channels of communication appropriate for interactive communication.

- Empathy: Caring, individualised attention given to customers and supportiveness.

- Reliability: Ability to perform the promised service dependably and accurately. 


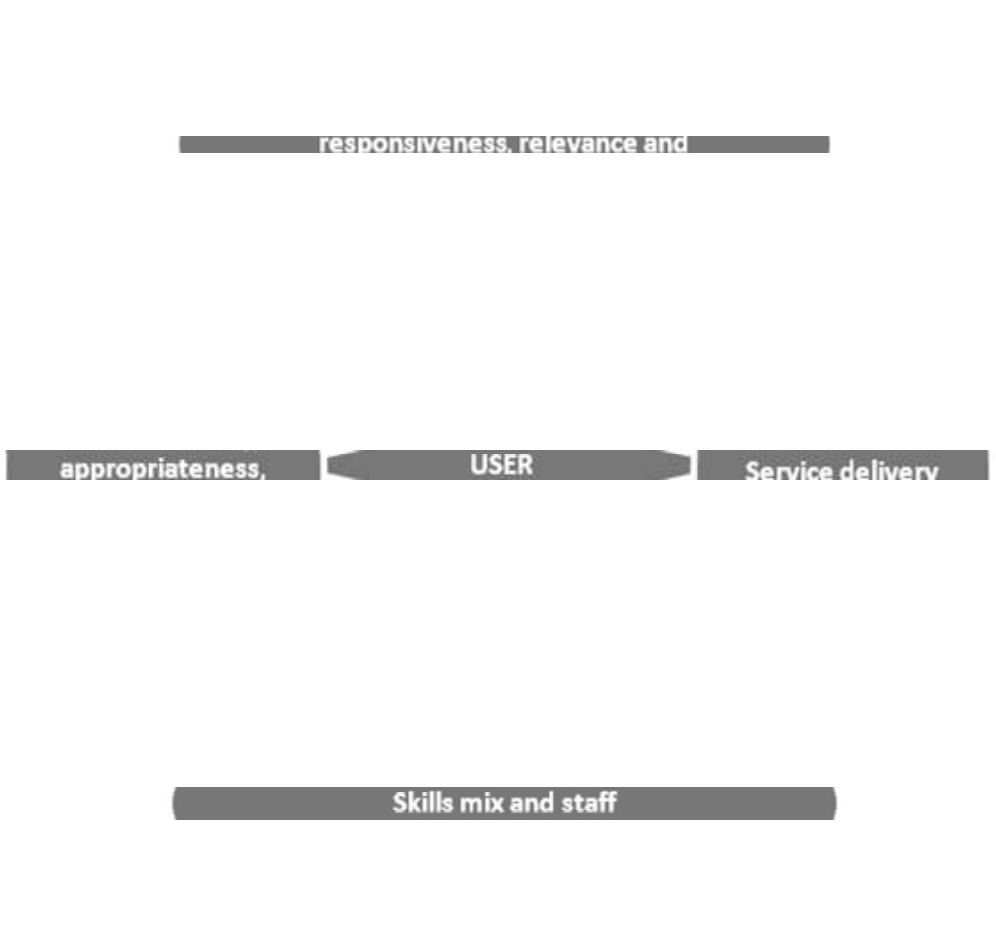

The user is depicted as the epicentre, the axis upon which revolves all work processes

Figure 1 Quality indicators for libraries

\subsubsection{Collection: range, relevance and accessibility}

The primary goal of the library is to select, collect, organize and provide access to all varieties of information sources. The following attributes are appropriate for determining the depth, breadth, quality, accessibility, usability and relevance of media and services a library offers:

- Convenient access: The customer must have easy access to needed services and products.

- Relevance: It is the adequacy of the library collections.

- Usability: It is the level and extent of resource provision is aligned with skills empowerment so that customers are capable of independent usage of resources.

- Currency: It is the provision of current resources.

- Comprehensiveness: It is the ability to achieve objectives and fulfill needs of customers.

- Collection preservation: The library needs to have to have programmes to safeguard against loss, mutilation, theft, and destruction of materials through natural catastrophes.

\subsubsection{Service delivery}

Library services and products are designed and delivered to support the needs of users as follows:

- Customer relationship management: Ensuring that customer care and inclusitivity are prioritised to convey trust and confidence.

- Customer education programmes: Empowering users with mastery of information skills.

- Access (remote/virtual and/ or physical): Accessibility should be oriented towards the living circumstances and habits of users.

- Responsiveness: It is the willingness to provide prompt service oriented towards customer satisfaction.

- Reliability: It is the ability to perform the promised service dependably and accurately.

- Marketing and publicity: There is a process to ensure that services and products are marketed or publicised.

SA JnI Libs \& Info Sci 20I I, 77(I) 
4.2.1.4 Infrastructure and facilities: safety, appropriateness, adequacy and usability

The attributes listed below will enable the library to determine whether the goods, services, facilities and equipment provided are fit for purpose and properly maintained.

- Reflective, creative and adequate space: Reasonable space is provided in accordance with appropriate legislation to ensure a safe working environment for both staff and users.

- Good functional furniture: Appropriate for the different categories of users.

- Information technology (IT): Systems are in place to enable delivery of information services and resources in accordance with contractual and licensing agreements as well as local needs. Essentially, equipment should be appropriate, adequate, usable and well maintained.

- Helpful directional signs: To map out the physical space that will enable users to find needed services quickly and independently.

- Good sanitary facilities: Appropriate for the different categories of users.

- Good lighting: Appropriate for the use of and maintenance of stock / materials.

- Convenient opening hours: Oriented towards the living circumstances and habits of users.

\section{Research methodology}

The study utilised survey to yield relevant insights from the participants about quality assurance initiatives and experiences in university libraries. It utilised questionnaires to collect empirical data, and at a secondary level theoretical data was collected from relevant institutional documents and related literature. The study applied triangulation in order to enrich findings and also ensure credibility, validity and reliability. Against the preceding background, the study used the following indicators as a basis for designing questionnaire items:

- Elements of quality framework - policy, integration and purpose statement;

- skills mix and staff;

- collection range, relevance and accessibility;

- library services;

- infrastructure and facilities; and

- innovative quality assurance initiatives and problems encountered.

Questionnaires were administered to library officials who deal with quality assurance matters or issues. The study targeted academic libraries from universities that were chosen purposively using the variable of typology or classification. Firstly, University of South Africa (Unisa), Walter Sisulu University (WSU), Universities of Johannesburg (UJ) and Zululand (UNIZULU) are comprehensive institutions. Secondly, Universities of KwaZulu-Natal (UKZN), Western Cape (UWC), Limpopo (UNIL) and Pretoria (UP) are traditional universities. Thirdly, Durban (DUT), Tshwane (TUT), Central (CUT) and Mangosuthu (MUT) are all universities of technology.

\section{Results and discussions}

Out of 12 universities targeted only 5 (42\%) responded to the questionnaire. These are Unisa, UWC, UP, TUT and CUT. This being a qualitative study, it is permissible to have a smaller but focused sample. Grounded on the fitness for purpose model, the study utilised the indicators presented earlier to determine the range of quality practices in academic libraries. The results are integrated and presented using the variable of typology to retain anonymity.

\subsection{Quality Assurance Officer}

A question was asked to determine whether libraries have a dedicated quality assurance office or officer. Having personnel dedicated to quality assurance matters gives the impression that the library regards such matters seriously. On the other hand, having it dealt with as an add-on responsibility somehow compromises the extent, nature and commitment to quality assurance matters. In answering the question, only one institution which is a traditional university has a dedicated Quality Assurance Team, one institution which is a comprehensive university has a Quality Assurance Officer. The other three libraries indicated that quality is not treated as a separate entity, but is integrated into other operations. It is as such a responsibility all staff members handled.

\subsection{Purpose statement}

Respondents were asked to indicate their purpose statement. Given the fact that academic libraries are part of universities whose quality initiatives are judged by the HEQC according to the fitness for purpose model, it was seen appropriate to question the purpose statement. Generally, academic institutions serve curricular, research and outreach functions of the institution. Summarily, informants indicated that their purpose statement entails managing information and knowledge. It also entails providing mastery of a range of information forms and formats, creating appropriate conditions for independent learning for a diverse client base in a manner that supports academic functions.

SA JnI Libs \& Info Sci 20I I, 77(I) 


\subsection{Integration}

Integration entails the alignment of library goals with those of the institution. Because the essence of the academic library is to support academic functions, it is critical that there is congruence between library goals and institutional ones. Generally, respondents claimed that their plans, objectives, goals and targets are in alignment with the institutional strategic direction.

\subsection{Quality assurance policy framework}

The essence of a quality assurance policy is to inform, guide and standardise quality practices. Regarding the existence of a quality assurance policy framework in libraries, all the informants indicated that their libraries do not have the policy. One library indicated having a strategy instead of a policy. Policies differ from strategies in that they are guiding principles, rules or statements, intended to influence decisions and actions whilst strategies are rather high level plans delivering change. Even though they do not have a policy framework, informants indicated that quality is integrated into their dayto-day operations. It is not treated as a separate entity. In the absence of a policy framework, informants indicated that their quality assurance practices are informed by various exercises as depicted in Table $\mathrm{I}$.

Table I Framework informing quality direction

\begin{tabular}{|l|l|l|}
\hline Traditional Universities & Universities of Technology & Comprehensive Universities \\
\hline Library quality assurance strategy & $\begin{array}{l}\text { Institutional policies, guidelines and procedures on } \\
\text { quality assurance }\end{array}$ & $\begin{array}{l}\text { Institutional policies, guidelines and procedures } \\
\text { on quality assurance }\end{array}$ \\
$\begin{array}{l}\text { Feedback from clients / customers } \\
\text { gathered through service evaluations, } \\
\text { client surveys and task analysis }\end{array}$ & $\begin{array}{l}\text { Feedback from clients / customers gathered through } \\
\text { service evaluations, client surveys and task analysis }\end{array}$ & $\begin{array}{l}\text { Feedback from relevant structures such as } \\
\text { Library Committees and the Library Data } \\
\text { Governance Forum }\end{array}$ \\
$\begin{array}{l}\text { International library quality assurance } \\
\text { discourse and best practice }\end{array}$ & $\begin{array}{l}\text { Feedback from relevant structures such as Faculty } \\
\text { Boards and Library Committees }\end{array}$ & $\begin{array}{l}\text { CHELSA guidelines } \\
\text { (Refer to 4.I) }\end{array}$ \\
$\begin{array}{l}\text { CHELSA guidelines } \\
\text { (Refer to 4.I) }\end{array}$ & & \\
\hline
\end{tabular}

It is good that there is a library with a quality assurance strategy, whilst others libraries are only guided by feedback from either clients or institutional structures regarding quality matters. The limitations of not having guiding principles maybe lack of commitment or a strategic direction, haphazard operations or initiatives and lack of improvement and growth towards the development of a quality culture. As indicated in earlier sections in 2006 CHELSA developed a common framework of guidelines with suggested indicators that can be used to evaluate quality in an academic library, these are the same guidelines that some libraries have used.

\subsection{Quality assurance initiatives}

To determine the typology, extent and nature of quality assurance practices, respondents were asked to indicate the quality assurance initiatives that their libraries have adopted. The results are depicted in Table 2.

Table 2 How university libraries assure quality

\begin{tabular}{|l|l|l|}
\hline Traditional Universities & Universities of Technology & Comprehensive Universities \\
\hline $\begin{array}{l}\text { Conducting service evaluations and client } \\
\text { surveys using tools different tools such as } \\
\text { LibQUAL+ and in-house surveys. }\end{array}$ & $\begin{array}{l}\text { Conducting service evaluations and client surveys } \\
\text { using tools in-house surveys. }\end{array}$ & $\begin{array}{l}\text { Developing an online quality management } \\
\text { system. }\end{array}$ \\
$\begin{array}{l}\text { Using LibQUAL+ results to benchmark } \\
\text { services with other academic libraries. }\end{array}$ & & $\begin{array}{l}\text { Encouraging library staff members to complete } \\
\text { a course in the basics of Total Quality Manage- } \\
\text { ment (TQM). }\end{array}$ \\
$\begin{array}{l}\text { Conducting peer or external reviews } \\
\text { library services and processes. }\end{array}$ & Using CHELSA guidelines. \\
$\begin{array}{l}\text { Getting involved in international library } \\
\text { quality assurance discourse and best } \\
\text { practice. }\end{array}$ & & \\
Using CHELSA guidelines. & & \\
\hline
\end{tabular}


Table 3 Knowledgeability of staff and good customer relations management

\begin{tabular}{|c|c|c|}
\hline Traditional Universities & Universities of Technology & Comprehensive Universities \\
\hline \multicolumn{3}{|c|}{ How libraries make certain that staff is knowledgeable in their areas of responsibility } \\
\hline $\begin{array}{l}\text { Recruit and appoint staff with good knowledge, } \\
\text { skills and experience whenever possible. } \\
\text { Conduct induction programmes. }\end{array}$ & Provide regular training interventions for staff. & $\begin{array}{l}\text { Recruit and appoint staff with good knowledge, } \\
\text { skills and experience whenever possible. } \\
\text { Conduct induction programmes. }\end{array}$ \\
\hline Provide regular training interventions for staff. & $\begin{array}{l}\text { Encourage staff members to attend regularly } \\
\text { workshops, seminars, conferences. These are } \\
\text { seen as platforms appropriate for sharing best } \\
\text { practices. }\end{array}$ & Provide regular training interventions for staff. \\
\hline $\begin{array}{l}\text { Encourage to attend regularly workshops, } \\
\text { seminars, conferences. These are seen as } \\
\text { platforms appropriate for sharing best } \\
\text { practices. }\end{array}$ & $\begin{array}{l}\text { Institutional performance evaluation } \\
\text { procedures also help map out performance and } \\
\text { gaps, and identify gaps thereof. }\end{array}$ & $\begin{array}{l}\text { Encourage to attend regularly workshops, } \\
\text { seminars, conferences. These are seen as } \\
\text { platforms appropriate for sharing best } \\
\text { practices. }\end{array}$ \\
\hline $\begin{array}{l}\text { The library and the institution conduct } \\
\text { performance evaluation procedures also help } \\
\text { map out performance and gaps, and identify } \\
\text { gaps thereof. }\end{array}$ & & $\begin{array}{l}\text { Institutional performance evaluation } \\
\text { procedures also help map out performance and } \\
\text { gaps, and identify gaps thereof. }\end{array}$ \\
\hline \multicolumn{3}{|c|}{ How libraries ensure that staff practise good customer relations management } \\
\hline The library has a staff development plan. & $\begin{array}{l}\text { Staff training interventions are organised } \\
\text { accordingly. }\end{array}$ & The library has a staff development plan. \\
\hline $\begin{array}{l}\text { Staff training interventions are organised } \\
\text { accordingly. }\end{array}$ & $\begin{array}{l}\text { Mentorship programmes for new staff to } \\
\text { familiarise them with best practice. }\end{array}$ & $\begin{array}{l}\text { Staff training interventions are organised } \\
\text { accordingly. }\end{array}$ \\
\hline $\begin{array}{l}\text { Mentorship programmes for new staff to } \\
\text { familiarise them with best practice. }\end{array}$ & $\begin{array}{l}\text { Regular discussions to create a consistent } \\
\text { 'mental model' }\end{array}$ & $\begin{array}{l}\text { Mentorship programmes for new staff to } \\
\text { familiarise them with best practice. }\end{array}$ \\
\hline The library has a Service Charter. & The library has a Code of Ethics. & The library has a Code of Ethics. \\
\hline $\begin{array}{l}\text { Provision for clients to give positive or negative } \\
\text { feedback. }\end{array}$ & $\begin{array}{l}\text { Provision for clients to give positive or } \\
\text { negative feedback. }\end{array}$ & $\begin{array}{l}\text { Provision for clients to give positive or negative } \\
\text { feedback. }\end{array}$ \\
\hline $\begin{array}{l}\text { Regular discussions to create a consistent } \\
\text { 'mental model'. }\end{array}$ & & $\begin{array}{l}\text { Institutional performance evaluation } \\
\text { procedures conducted regularly. }\end{array}$ \\
\hline $\begin{array}{l}\text { Institutional performance evaluation procedures } \\
\text { conducted regularly. }\end{array}$ & & \\
\hline
\end{tabular}

Generally, most respondents use evaluations to assure quality. Evaluations generally have a two-year cycle for evaluations as they indicated that they last did them in 2008, and the next ones are scheduled for 2010. Determining the contents of tools used in the user evaluations mentioned above was beyond the scope of this study. As indicated earlier, it has come out strongly from the literature that most libraries are still oriented towards quantitative surveys that focus on the statistics of inputs, notwithstanding their usefulness Poll (2008) cautions they need to be strengthened by qualitative data drawn from outputs and outcomes. Interestingly one library which was one of the seven libraries chosen for the LibQual+ surveys in 2005 they have used the results also for benchmarking purposes. Besides the evaluations there are other initiatives such as conducting an external review of the library, developing an online quality management system and using CHELSA guidelines. It is commendable that libraries have a wide scope of quality initiatives beyond user or client surveys. It would even be more praiseworthy if outcomes from such initiatives would feed into planning, enhancing continuous improvement, which is what quality assurance is all about.

\subsection{Staff and skills mix}

It is known fact that staff skills, knowledge and attitude as well as their satisfaction levels have direct impact on the quality of service. As a result, a question was asked to determine how libraries ensure that staff is knowledgeable in their areas of responsibility. Additionally, informants were asked how the library ensures that members of staff practise good customer relations management. The question was asked because the essence of quality assurance is on the one hand to increase 
customer satisfaction and retention and on the other enhance the organisation's credibility and improve work processes and efficiency. Responses to both questions are presented in Table 3.

The responses in Table 3 show similarities across the board and it is exciting to see that libraries generally consider the knowledgeability of staff as well as customer necessarily yield good results a question was asked to determine what happens to employees who do not practice good customer care. Generally responses given specified that:

- Reasons for bad practice are investigated, problems are discussed and appropriate measures are taken according to institutional guidelines. Measures taken may be developmental (training) or punitive (disciplinary) depending on the merits of each case.

- Ongoing performance evaluation is done to identify skills gaps which inform further training opportunities.

- Provision is made for users to express concerns, complaints, recommendations as well as commendations by reporting directly through librarians or management. Alternatively by using suggestion boxes, the telephone or e-mail.

- Feedback is also solicited through tools such tools as LibQUAL+ and in-house surveys.

6.7 Library services

One of the quality indicators discussed earlier is the delivery of library services which basically entails the thrust or essence of a library. To have a view of their scope of functions, libraries were asked to indicate how they ensure the following:

\subsection{Accessibility of resources}

Ideally, a library should endeavor to provide equitable access to its extensive collections through a multi-tiered service delivery model which rationalises the location, scope and focus of collections. In response to the question about accessibility, all respondents indicated they have online sources that can be accessed in the library or from remote locations. These are online journals and databases, OPAC and Google Scholar. One library in particular also uses PRIMO and Open Worldcat. About three libraries indicated that they have branch libraries that help to decentralise services and bring them closer to the user. Additionally, for all libraries access is enhanced through interlending services, others use postal services to address requests for printed documents and interestingly one library stated that researchers are granted visiting rights. Lastly, and importantly libraries indicated that access is enhanced by providing relevant training to users.

\subsubsection{Relevance of sources}

A question was asked to determine the timeliness or aptness of library collections. The responses given ranged from:

- Having a dedicated collection development team;

- Having a collection development policy;

- Conducting regular evaluation of resources;

- Conducting client surveys that usually give direct and indirect pointers;

- Importantly, soliciting recommendations from academic staff; and

- Using faculty/ school or departmental plans to inform purchasing decisions.

\subsubsection{Currentness of sources}

It is vital that the library should keep up-to-date sources. To ensure that this function is achieved, libraries generally do the following:

- They establish a collection development team to procure material with user's needs in mind.

- They perform weeding regularly.

- Others use statistical lists, for instance, with Millenium to see the age and usage of stock.

\subsubsection{Efficacy of retrieval tools}

Retrieval tools play a vital role in the accessibility of information resources. Libraries were asked how they ensure the efficacy of retrieval tools (see Table 4).

\subsubsection{End-user instruction}

As information providers libraries have a responsibility, among other things, to provide mastery of a range of information forms and formats. To this effect, it was indicated that:

- Two libraries have a customer training unit that provides user instruction as per demand.

- Four libraries conduct orientation programme for first year students.

- One library indicated that it conducts information and ongoing skills training for general users as needed.

- In one institution, the academic Department of Information Science provides credit bearing Information Literacy course for students.

- About four indicated that they provide manuals, online training and database training, especially for postgraduate students. 
Table 4 Efficacy of retrieval tools

\begin{tabular}{|l|l|l|}
\hline Traditional Universities & Universities of Technology & Comprehensive Universities \\
\hline $\begin{array}{l}\text { Being able to add modules as required, to } \\
\text { ensure optimal retrieval of information. }\end{array}$ & $\begin{array}{l}\text { Having close collaboration with the Information } \\
\text { Communication Technology (ICT) Department. }\end{array}$ & $\begin{array}{l}\text { Having state of the art retrieval Library } \\
\text { Management System. }\end{array}$ \\
$\begin{array}{l}\text { Having close collaboration with the } \\
\text { Information Communication Technology } \\
\text { (ICT) Department. }\end{array}$ & Maintaining an up-to-date catalogue. & Maintaining an up-to-date catalogue. \\
$\begin{array}{l}\text { Analysing and usage of statistics per resource } \\
\text { platform. }\end{array}$ & Conducting catalogue spot checks. & \\
Analysing hits (Google Scholar). & Analysing hits (Google Scholar). & \\
\hline
\end{tabular}

\subsubsection{Alignment of customer needs with delivered service}

It emerged from the responses that generally libraries align customer satisfaction with delivered service by conducting regular customer surveys. The results from such surveys are analysed extensively and fed into planning. Decisions on changes that will or will not be implemented are communicated to clients. Although all institutions expressed these sentiments only two of them have a dedicated Quality Assurance unit/ officer. might compromise the depth and breadth of surveys conducted by those who do not have such resources.

\subsubsection{Speed of response time}

Only three informants answered this question and they indicated that they determine the turnaround time for request services by measuring search services, information services and interlending. And the results are integrated into the library's improvement plans. However, concerns were raised about delays that are beyond the control of the library usually caused by information technology (IT) problems, suppliers or vendors.

\subsubsection{Marketing and promotion of services}

To popularise their services, it was stated that:

- Two libraries have a dedicated division for library marketing.

- For three libraries, the library works closely with the relevant university structures to ensure marketing of services to regular and potential clients.

- Some use sign posts and exhibitions, brochures, plasma screens, the library and university websites.

- One library in particular uses services such as Ask-a-Librarian.

- Others conduct regular visits to academic departments.

- Others market their services during training interventions, when they conduct client surveys and programmes scheduled during library week celebrations.

\subsubsection{Innovativeness}

Libraries indicated that innovativeness is encouraged and the following are few examples of initiatives that are in place (see Table 5).

\begin{tabular}{|l|l|l|}
\hline \multicolumn{2}{|l|}{ Table 5 Innovativeness } & Comprehensive Universities \\
\hline Traditional Universities & Universities of Technology & Revolutionary self-help services. \\
\hline $\begin{array}{l}\text { Review of the library by peers/ external } \\
\text { experts. }\end{array}$ & Automation of processes, e.g. ordering. \\
$\begin{array}{l}\text { Paying particular attention to new tools, } \\
\text { products and services in the electronic } \\
\text { environment. }\end{array}$ & $\begin{array}{l}\text { Holding regular meetings to acknowledge and } \\
\text { share best practices among colleagues. }\end{array}$ & $\begin{array}{l}\text { Paying particular attention to new tools, products } \\
\text { and services in the electronic environment. }\end{array}$ \\
Using web 2.0 tools. & $\begin{array}{l}\text { Promoting the use of different technologies to } \\
\text { enhance accessibility of resources. }\end{array}$ \\
\hline
\end{tabular}




\subsubsection{Problems encountered}

The problems concerning quality assurance that were unearthed are very limited as only one respondent answered the question. Financial constraints were mentioned as the major problem affecting negatively the overall functions of the library.

\subsection{I Infrastructure and facilities}

Regarding the question on the appropriateness of space provision, availability of functional furniture and appropriate IT, the following answers were given:

- Almost all informants indicated that they conduct regular surveys of physical facilities / usability studies to help ongoing development and repurposing of available space in accordance with institutional directives and budget provisions.

- In other libraries there are possibilities of renovating facilities, whilst in others there are financial constraints.

- Libraries try within budgetary constraints to procure appropriate furniture for different categories of users.

- There seems to be a discrepancy between the different libraries regarding IT systems available. Others seem to have state of the art IT systems and tools such as PRIMO, Open Worldcat and web 2.0 tools, whilst others have the more regular ones.

\section{Conclusions and recommendations}

\subsection{Conclusions}

The intent of the paper was to assess the extent and nature of quality assurance practices implemented by academic libraries in South Africa. After 1994 the introduction of quality initiatives in the higher education sector brought about the realisation that academic libraries need to pay serious attention to quality matters. Subsequently, since the inception CHELSA a framework to guide quality assurance practices in academic libraries was developed. Against this preceding background the results show that libraries are at different levels in as far as assuring quality is concerned. The following indicators were used to determine quality strategies adopted by the participant libraries: skills mix and staff; collection range, relevance and accessibility; library services; infrastructure and facilities; and innovative quality assurance initiatives. The objectives of the study were achieved as quality indicators were mapped, quality assurance strategies were examined and challenges were identified. However, there is a sense that all of them are conscious of quality issues and are committed to continuous improvement and satisfying the needs of the customer.

\subsection{Recommendations}

- As there institutions which have active and integrative processes for maintaining and improving quality the study underscores the need to share best or ideal practices as this could strengthen quality assurance practices across the sector.

- It would be advisable for libraries to appoint Quality Assurance Officers as those libraries with dedicated officers seemed to be doing intense work on quality assurance.

- The CHELSA guidelines could be streamlined to serve a model to guide quality assurance in academic libraries.

\section{References}

ALA Standards for University Libraries: evaluation of performance. 1989. [Online]. http://sacs.uah.edu/documents/policies/ Salmon Library ala. (Accessed 16 September 2010).

Balog, KP. 2009 . Measuring Croatian public and academic library culture. Performance Measurement and Metrics I0 (3): $220-235$.

CHELSA. 2006. Guide to the self review of university libraries. Prepared by the members of the Quality Assurance Subcommittee of the Committee for Higher Education Librarians of South Africa.

Department of Education (South Africa). 1997. Education White Paper 3. A Programme for the transformation of Higher Education. General notice. Notice II 96 of 1997.

Ford, G. 1990. Review of method employed in determining the use of library stock. London: British National Bibliography Research Fund Report 43.

Kinnell, M., Usherwood, B. \& Jones, K. 1999. Improving library and information services through self-assessment: a guide for senior managers and staff developers. London: Library Association. British Library Research and Innovation Report 172.

Gozo, AJ. 2007. The fast track in library evaluation: the South African experience in higher education libraries. World Library and Information Congress: 73rd IFLA General Conference and Council (WLIC) 19-23 August 2007, Durban, South Africa. [Online]. http://www.ifla.org/iv/ifla73/index.htm. (Accessed 19 April 2010).

Majid, S., Anwar, M.A \& Eisenschitz, T.S. (200I). User perceptions of library effectiveness in Malaysian agricultural libraries. Library Review, 50 (4): 176-187.

Mdlalose, CN. 2004. Access to scholarly information as a requisite for research, innovation and development: creating and maintaining a democratic society. [Online]. http://www.liasa.org.za/conference2004/papers/LIASA-Conference-2004-Mdlalos.pdf. (Accessed 19 April 2010).

McGregor, F. 2004. Excellent libraries: a quality assurance perspective. Advances in Librarianship, 28: 17-53. [Online]. http:// ro.uow.edu.au/asdpapers/27. (Accessed I3 February 2010).

Moon, A. 2007. LibQUAL+TM at Rhodes University Library: an overview of the first South African implementation. Performance Measurements and Metrics, 8 (2): 72-87. 
Poll, R. 2006. Impact measures for libraries and information services. Library Hi Tech 24 (4): 547-562. [Online]. http:// conference.ub.unibielefeld.de/2006/proceedings/payne_poll_final_web.pdf. (Accessed I2 December 20I0).

Poll, R. 2008. High quality - high impact? Performance and outcome measures in libraries. The Hague: International Federation of Library Associations (IFLA).

Snoj, B. \& Petermanec, Z. 200I. Let users judge the quality of faculty library services. New Library World, I02 (I I68): 3 I4-325.

Tam, LWH. 2000. Quality management theory and practice: some observations of practices in Australian academic libraries. Library Management, 21 (7):349-356.

Tiemensma, L. 2009. Quality metrics in academic libraries: striving for excellence. Paper presented at the QQML2009: Qualitative and Quantitative Methods in Libraries, International Conference, Chania Crete Greece, 26-29 May 2009. [Online]. http://www.isast.org/proceedingsQQML2009/PAPERS_PDF/Tiemensma-Quality_metrics_in_academic_libraries_PAPERQQML2009.pdf. (Accessed 4 April 20II.

UNESCO - International Institute for Educational Planning. 2006. Understanding and assessing quality. Module 4. External quality assurance: options for higher education managers, Paris. [Online]. http://www.iiep.unesco.org/fileadmin/user. (Accessed 2l April 20l0).

Vergueiro, W\& De Carvalho, T. (n.d.). Quality in Brazilian Libraries: proposal of indicators from the customers' point of view. University of Sao Paulo. [Online]. http://www.cais-acsi.ca/proceedings/2000/vergueiro. (Accessed I2 March 2010).

Winkworth, I. 200 I. Innovative United Kingdom approaches to measuring service quality. Library Trends, 49 (4): 7 I 8-73I .

Zeithaml, V.A, Bitner, M.J. \& Gremler, D.D. 2006. Services marketing: Integrating customer focus across the firm. Boston: McGraw-Hill. 